\title{
Demystifying roots: A need for \\ clarification and extended concepts in root phenotyping
}

Guillaume Lobet ${ }^{1}$, Ana Paez-Garcia², Hannah Schneider ${ }^{3}$, Astrid Junker ${ }^{4}$, Jonathan Atkinson ${ }^{5}$, Saoirse Tracy ${ }^{6}$,

\section{Corresponding author}

Email address: saoirse.tracy@ucd.ie

Full postal address: School of Agriculture and Food Science, University College Dublin, Ireland.

Key words:

root, phenotyping, plasticity, ontology

\section{Highlights:}

- Root phenotyping is a growing field in plant biology

- Terminology used in root phenotyping papers is diverse and inconsistent

- There is a need for better and wider use of unified ontologies

- There is a need for expanding current ontologies to incorporate plasticity concepts 


\section{Authors affiliations}

\begin{tabular}{|c|c|c|c|}
\hline First Name + Last Name & Affiliation & e-mail & orcid \\
\hline Jonathan Atkinson & $\begin{array}{l}\text { The Centre for Plant } \\
\text { Integrative Biology, School } \\
\text { of Biosciences, University } \\
\text { of Nottingham, Sutton } \\
\text { Bonington, UK }\end{array}$ & $\begin{array}{l}\text { jonathan.atkinso } \\
\text { n@nottingham. } \\
\text { ac.uk }\end{array}$ & 0000-0003-2815-0812 \\
\hline Astrid Junker & $\begin{array}{l}\text { Heterosis Group, Dept. of } \\
\text { Molecular Genetics at } \\
\text { Leibniz Institute of PLant } \\
\text { Genetics and Crop Plant } \\
\text { Research (IPK) } \\
\text { Gatersleben, Germany }\end{array}$ & $\begin{array}{l}\text { junkera@ipk-gat } \\
\text { ersleben.de }\end{array}$ & $\begin{array}{l}0000-0002-4656-030 \\
8\end{array}$ \\
\hline Guillaume Lobet & $\begin{array}{l}\text { Agrosphere, IBG3, } \\
\text { Forschungszentrum Jülich, } \\
\text { Jülich, Germany \& Earth } \\
\text { and Life Institute, } \\
\text { Université catholique de } \\
\text { Louvain, } \\
\text { Louvain-la-Neuve, } \\
\text { Belgium. }\end{array}$ & $\begin{array}{l}\text { g.lobet@fz-jueli } \\
\text { ch.de }\end{array}$ & $\begin{array}{l}0000-0002-5883-457 \\
2\end{array}$ \\
\hline Ana Paez-Garcia & $\begin{array}{l}\text { Noble Research Institute, } \\
\text { LLC } \\
\text { Ardmore, Oklahoma, US }\end{array}$ & $\begin{array}{l}\text { apaezgarcia@n } \\
\text { oble.org }\end{array}$ & $\begin{array}{l}0000-0002-2006-868 \\
1\end{array}$ \\
\hline Hannah M. Schneider & $\begin{array}{l}\text { Department of Plant } \\
\text { Science, The Pennslyvania } \\
\text { State University, University } \\
\text { Park, USA }\end{array}$ & $\begin{array}{l}\text { hms221@psu.e } \\
\text { du }\end{array}$ & $\begin{array}{l}0000-0003-4655-625 \\
0\end{array}$ \\
\hline Saoirse Tracy & $\begin{array}{l}\text { School of Agriculture and } \\
\text { Food Science, University } \\
\text { College Dublin, Ireland. }\end{array}$ & $\begin{array}{l}\text { saoirse.tracy@u } \\
\underline{\text { cd.ie }}\end{array}$ & $\underline{\underline{0000-0002-0251-67}}$ \\
\hline
\end{tabular}




\section{Abstract}

Plant roots have major roles in plant anchorage, resource acquisition and offer environmental benefits including carbon sequestration and soil erosion mitigation. As such, the study of root system architecture, anatomy and functional properties is of crucial interest to plant breeding, with the aim of sustainable yield production and environmental stewardship.

Due to the importance of the root system studies, there is a need for clarification of terms and concepts in the root phenotyping community. In particular in this contribution, we advocate for the use of a reference naming system (ontologies) for roots and root phenes. Such uniformity would not only allow better understanding of research results, but would also enable a better sharing of data. In addition, we highlight the need to incorporate the concept of plasticity in breeding programs, as it is an essential component of root system development in heterogeneous environments.

\section{Graphical abstract}

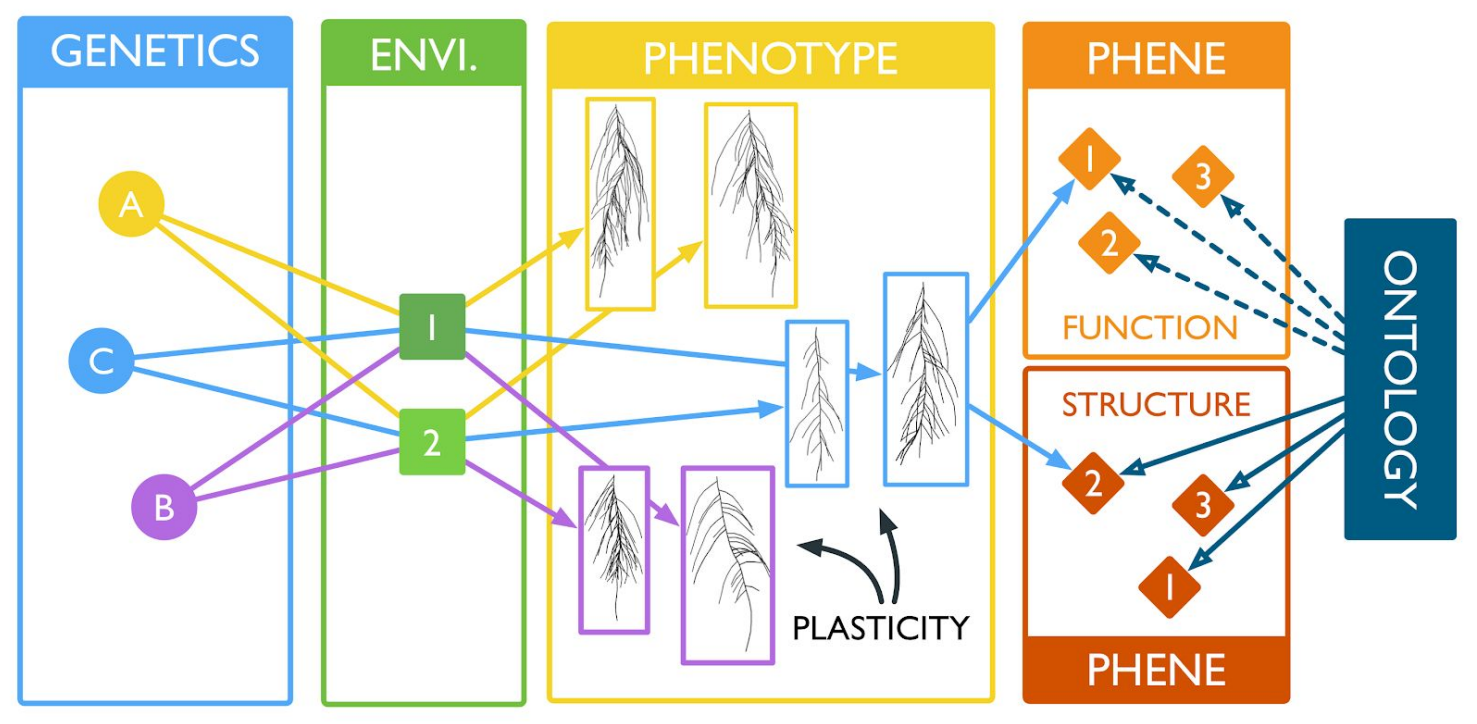




\section{Definitions}

The study of root system morphology, anatomy and spatial distribution (root architecture) is challenging due the "hidden" nature of these organs and their complexity. Recent interest in root phenotyping and genetics has enabled the creation of new terminology that describes root phenotypes, structures, and functions. For instance, the Planteome website

http://planteome.org/) [1] is a useful tool for plant scientists to unify terminology. This integrative initiative aims to bring together common annotations or standards and a group of reference ontologies for plants, with the desire that they will be used by researchers as a common language and will facilitate the integrated analysis of large data sets from different data repositories. Plant Trait Ontology is one of the reference ontologies that can be found at Planteome site, and describes specific measurable phenes, although the list of root traits focuses on architectural features is so far omitting any physiological root traits.

It would be advantageous to use tools like the previous-mentioned ones in publications and at conferences to standardise the use of root nomenclature, in order to speak the same language within the root phenotyping community. Despite the obvious gain that a systematized nomenclature can bring to the scientific community, a consistent application of standard root terminology has not yet been achieved. For instance, discrepancies in the name of root types can even be found in the same plant species between publications. Efforts have been made in this regard, leading to a root system architectural taxonomy that defines the main roots classes present in nature: taproots, lateral roots, shoot-borne roots and basal roots; considering the origin of the root type [2]. There are also studies that aim to establish the definition of specific 
root phenes, such as root insertion angle and its components, along with different methods for analysing their plastic response under different environmental conditions $[3,4]$.

The lack of adoption of common terminology might be due to an unawareness of such resources by researchers, or an inadequacy between the existing terms and researchers needs. With the ever-increasing use of phenotypic techniques that enable imaging, quantification and modelling of complex root systems by studying phenes at macro and micro scale, the need to integrate biology and computational methodologies is increasingly apparent [5]. Therefore, there is a demand (and a need) to create a common language where these two disciplines can start a successful dialogue, leading to a better understanding of plant morphology and development [6]. Efforts and discussions throughout the entire community are needed to achieve such a goal.

\section{Plasticity}

Successful crop varieties are often selected in a specific soil type, climate, and agricultural management practice, a static environment where a specific root ideotype can be effective for crop yield. However, decreasing freshwater availability, rising costs of fuel and nitrogen fertilizer and unpredictable growing environments due to climate change require the development of crop varieties that are increasingly adaptable in order to maintain high and stable yields [7-10]. Phenotypic plasticity and Genotype and Environment $(G \times E)$ interaction have often been considered a challenge in phenotyping and breeding programs [11,12]. Modern breeding programs and agricultural productivity have typically been focused on selecting varieties with greater stability and uniformity rather than highly plastic genotypes, but perspectives on that are changing $[13,14]$. The identification of environmental sensing genes may enable targeted 
breeding for phenotypic plasticity [15].The development of new crop varieties can take years, and therefore selection of performance in the current environment may not hold-up in future environments and climates. Crop varieties able to adapt their growth in response to environmental cues may be a breeding target for addressing the growing world food demand, particularly in low input agriculture areas [16].

Phenotypic plasticity is the ability of an organism to change its phenotype in response to environmental cues [15] and does not explicitly improve plant performance or survival. Plastic responses may be of short or long duration. For example, the final diameter of a root is established after tissue growth, and while growing tissues may respond to the local environment, mature tissue does not. In contrast, expression of nitrate transporters may change to track environmental signals that fluctuate on short time scales. Phenotypic plasticity may be allocational, morphological, anatomical, or developmental [17], is under genetic control (e.g. [7]), and encompasses components of the interaction between genotype and environment, adaptation, and acclimation.

$G \times E$ interaction, or the differential response of genotypes to different environmental signals, is a type of plasticity. However, plasticity does not always imply a $G \times E$ interaction. Acclimation and adaptation are also types of plasticity that can have a $G \times E$ response as well, (Fig. 1) but are usually considered to be a plastic response that enhances plant fitness and survival. Adaptation is the shift in genotypes and/or phenotypes over generations that facilitates enhanced fitness in a specific environment. Acclimation, is the physiological, biochemical, or morphological modifications to a phenotype that results from environmental challenges. 
However, these terms are not exclusive, for example, phenotypic plasticity can be adaptive and also have a $\mathrm{G} \times \mathrm{E}$ component $[18,19]$.

Depending on the environment, plants with a greater plasticity may have an advantage over plants with low plasticity (e.g. [20]). Root system architecture has been demonstrated to have large implications in plant stress tolerance and performance, and specific components of this architecture may have a plastic response to the environment [21]. In drought conditions, plasticity in root length density, total root length $[22,23]$ and lateral root length and density $[24,25]$ improve shoot biomass, water uptake, and photosynthesis in rice. In legumes, symbiotic interactions with different rhizobium species resulted in a plastic response of root length and lateral root density [26]. In soybean, metaxylem number increased under drought conditions improved root hydraulic conductivity, which reduces the metabolic cost of exploring water in deeper soil domains and enhanced water transport [27]. High yield stability has been shown to correlate with high root plasticity in drought and low phosphorus environments in rice [7] and phenological plasticity in wheat, sunflower, and grapevine [28]. In variable phosphorus supply, tap and fibrous root systems had different physiological (exudates) and morphological (surface area) plasticity responses [29]. Phenotypic plasticity may improve plant performance in variable environments and be an effective future breeding target.

In certain scenarios, phenotypic plasticity may also be maladaptive. For example, proliferation of lateral branches in response to localized patches of nutrients [30,31] may be beneficial for nitrogen capture [32], but potentially also maladaptive if mobile resources (such as nitrogen) move through the soil profile faster than roots can proliferate. It is also interesting to note that a recent meta analysis on invasive species has shown that under high resource environments, an 
increased plasticity was not correlated with increased fitness [33]. Understanding phenotypic plasticity and its genetic control may enable the selection of lines with greater or reduced plasticity to enhance plant productivity in specific environments.

Previous research has brought to light the idea of root system ideotypes, often meant as specific architectural traits suitable for the capture of specific soil resources in specific environments. Root architectural phenes have been demonstrated to be successful in specific environments, but can be functionally maladaptive in variable or non-target environments $[34,35]$. In the field, the plants may be exposed to multiple, simultaneous stresses. In environments with multiple, dynamic stresses that vary year-to-year, a phenotypically plastic root system may be the ideal ideotype for stable and high yielding crops. Immense untapped potential exists for exploiting phenotypic plasticity to enhance productivity of agricultural crops. The knowledge of the molecular mechanisms and the genes underlying root plasticity can contribute as tools for breeders to develop varieties better adapted to a wide range of environments. However, this requires the measurement of roots (and shoots) under contrasting and dynamic environments and even future climate scenarios. This, in turn, is based on respective technological developments for climatization in plant growth rooms and for root imaging and analyses. 
No Plasticity

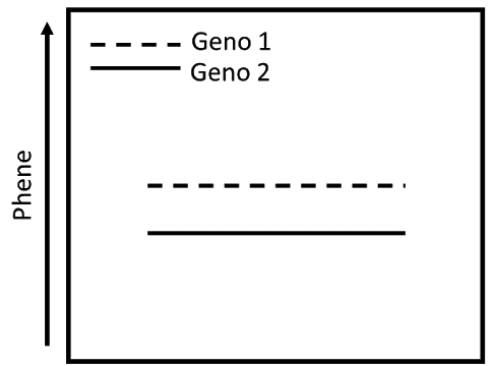

Env. 1

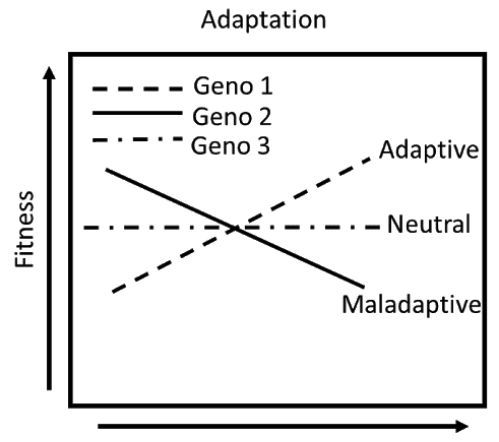

Plasticity
Plasticity, no GxE Interaction

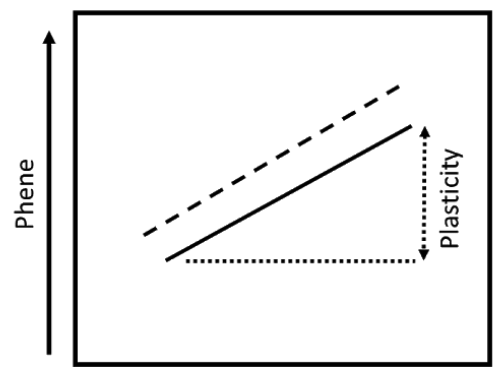

Env. 1

Env. 2

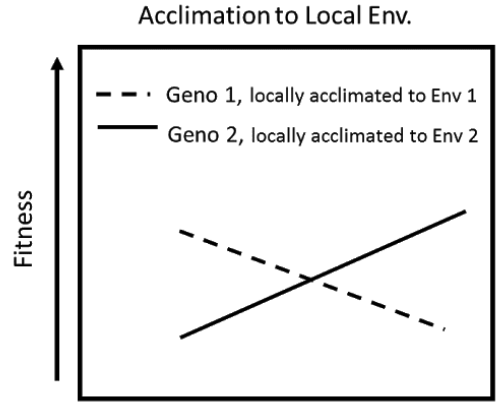

Env. 1

Env. 2

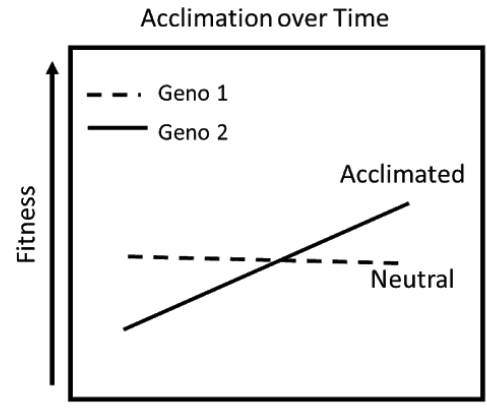

Year 1

Year 2

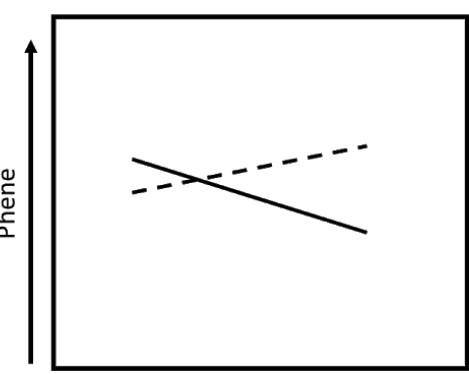

Env. 1

Env. 2

Acclimation over Time

Figure 1. Schematic of plastic responses. Plasticity can be adaptive, neutral, or maladaptive, may fluctuate temporally, and may have a G x E component. Phenotypic plasticity may be allocational, morphological, anatomical, or developmental.

\section{Acknowledgements}

This publication was written by attendees at the International Plant Phenotyping Network Symposium 2016. We are not necessarily proposing that the terminology suggested in this manuscript is perfect and it may not conform with other's opinions in the root phenotyping community. However, it is hoped that a common language can be discussed through a dialogue within the community. The attendees at the Roots workshop were (in alphabetical order): Jonathan Atkinson, Jose Luis Coyac, Xavier Draye, Kevin Falk, Trevor Garnett, Marcus Griffiths, Astrid Junker, Guillaume Lobet, Mohsen Mohammadi, Ana Paez-Garcia, Francisco Pinera, 
Amparo Rosero, Christophe Salon, Hannah Schneider, Stephan Summerer, Tove Sundgren, Saoirse Tracy and Khan Wahid.

\section{Literature cited}

[1] L. Cooper, P. Jaiswal, The Plant Ontology: A Tool for Plant Genomics, Methods Mol. Biol. 1374 (2016) 89-114.

[2] R.W. Zobel, Y. Waisel, A plant root system architectural taxonomy: A framework for root nomenclature, Plant Biosyst. 144 (2010) 507-512.

[3] J.P. Lynch, Root phenes for enhanced soil exploration and phosphorus acquisition: tools for future crops, Plant Physiol. 156 (2011) 1041-1049.

[4] L.M. York, E.A. Nord, J.P. Lynch, Integration of root phenes for soil resource acquisition, Front. Plant Sci. 4 (2013) 355.

[5] L.M. York, Functional phenomics: An emerging field integrating high-throughput phenotyping, physiology, and bioinformatics, bioRxiv. (2018) 370288. doi:10.1101/370288.

[6] M.A.F. Balduzzi, B.M. Binder, A. Bucksch, C. Chang, L. Hong, A.S. lyer-Pascuzzi, C. Pradal, E.E. Sparks, Reshaping Plant Biology: Qualitative and Quantitative Descriptors for Plant Morphology, Front. Plant Sci. 8 (2017). doi:10.3389/fpls.2017.00117.

[7] N. Sandhu, K.A. Raman, R.O. Torres, A. Audebert, A. Dardou, A. Kumar, A. Henry, Rice Root Architectural Plasticity Traits and Genetic Regions for Adaptability to Variable Cultivation and Stress Conditions, Plant Physiol. 171 (2016) 2562-2576.

[8] N. Brisson, P. Gate, D. Gouache, G. Charmet, F.-X. Oury, F. Huard, Why are wheat yields stagnating in Europe? A comprehensive data analysis for France, Field Crops Res. 119 (2010) 201-212.

[9] C. Tebaldi, D.B. Lobell, Towards probabilistic projections of climate change impacts on global crop yields, Geophys. Res. Lett. 35 (2008) L08705.

[10] J. Woods, A. Williams, J.K. Hughes, M. Black, R. Murphy, Energy and the food system, Philos. Trans. R. Soc. Lond. B Biol. Sci. 365 (2010) 2991-3006.

[11] M. Cooper, S. Fukai, L.J. Wade, How can breeding contribute to more productive and sustainable rainfed lowland rice systems?, Field Crops Res. 64 (1999) 199-209.

[12] K.E. Basford, M. Cooper, Genotypex environment interactions and some considerations of their implications for wheat breeding in Australia This review is one of a series commissioned by the Advisory Committee of the Journal, Aust. J. Agric. Res. 49 (1998) 153-174.

[13] A.D. Bradshaw, Unravelling phenotypic plasticity ? why should we bother?, New Phytol. 170 (2006) 644-648.

[14] B. Forde, Is it good noise? The role of developmental instability in the shaping of a root system, J. Exp. Bot. 60 (2009) 3989-4002.

[15] A.B. Nicotra, O.K. Atkin, S.P. Bonser, A.M. Davidson, E.J. Finnegan, U. Mathesius, P. Poot, M.D. Purugganan, C.L. Richards, F. Valladares, M. van Kleunen, Plant phenotypic plasticity in a changing climate, Trends Plant Sci. 15 (2010) 684-692.

[16] C.N. Topp, Hope in Change: The Role of Root Plasticity in Crop Yield Stability, Plant Physiol. 172 (2016) 5-6. 
[17] S.E. Sultan, Phenotypic plasticity for plant development, function and life history, Trends Plant Sci. 5 (2000) 537-542.

[18] W. Yamori, K. Hikosaka, D.A. Way, Temperature response of photosynthesis in C3, C4, and CAM plants: temperature acclimation and temperature adaptation, Photosynth. Res. 119 (2014) 101-117.

[19] P. Ren, Y. Meng, B. Li, X. Ma, E. Si, Y. Lai, J. Wang, L. Yao, K. Yang, X. Shang, H. Wang, Molecular Mechanisms of Acclimatization to Phosphorus Starvation and Recovery Underlying Full-Length Transcriptome Profiling in Barley (Hordeum vulgare L.), Front. Plant Sci. 9 (2018) 500.

[20] M.A. Molina-Montenegro, C. Galleguillos, R. Oses, I.S. Acuña-Rodríguez, P. Lavín, J. Gallardo-Cerda, C. Torres-Díaz, B. Diez, G.E. Pizarro, C. Atala, Adaptive phenotypic plasticity and competitive ability deployed under a climate change scenario may promote the invasion of Poa annua in Antarctica, Biol. Invasions. 18 (2016) 603-618.

[21] A. Hodge, The plastic plant: root responses to heterogeneous supplies of nutrients, New Phytol. 162 (2004) 9-24.

[22] M. Kano-Nakata, Y. Inukai, L.J. Wade, J.D.L.C. Siopongco, A. Yamauchi, Root Development, Water Uptake, and Shoot Dry Matter Production under Water Deficit Conditions in Two CSSLs of Rice: Functional Roles of Root Plasticity, Plant Prod. Sci. 14 (2011) 307-317.

[23] T.T. Tran, M. Kano-Nakata, R.R. Suralta, D. Menge, S. Mitsuya, Y. Inukai, A. Yamauchi, Root plasticity and its functional roles were triggered by water deficit but not by the resulting changes in the forms of soil $\mathrm{N}$ in rice, Plant Soil. 386 (2015) 65-76.

[24] M. Kano-Nakata, V.R.P. Gowda, A. Henry, R. Serraj, Y. Inukai, D. Fujita, N. Kobayashi, R.R. Suralta, A. Yamauchi, Functional roles of the plasticity of root system development in biomass production and water uptake under rainfed lowland conditions, Field Crops Res. 144 (2013) 288-296.

[25] M. Kano, Y. Inukai, H. Kitano, A. Yamauchi, Root plasticity as the key root trait for adaptation to various intensities of drought stress in rice, Plant Soil. 342 (2011) 117-128.

[26] C.-H. Goh, A.B. Nicotra, U. Mathesius, The presence of nodules on legume root systems can alter phenotypic plasticity in response to internal nitrogen independent of nitrogen fixation, Plant Cell Environ. 39 (2016) 883-896.

[27] S.J. Prince, M. Murphy, R.N. Mutava, L.A. Durnell, B. Valliyodan, J.G. Shannon, H.T. Nguyen, Root xylem plasticity to improve water use and yield in water-stressed soybean, J. Exp. Bot. (2017) erw472.

[28] V.O. Sadras, M.P. Reynolds, A.J. de la Vega, P.R. Petrie, R. Robinson, Phenotypic plasticity of yield and phenology in wheat, sunflower and grapevine, Field Crops Res. 110 (2009) 242-250.

[29] Y. Lyu, H. Tang, H. Li, F. Zhang, Z. Rengel, W.R. Whalley, J. Shen, Major Crop Species Show Differential Balance between Root Morphological and Physiological Responses to Variable Phosphorus Supply, Front. Plant Sci. 7 (2016) 1939.

[30] M.C. Drew, L.R. Saker, Nutrient supply and the growth of the seminal root system in barley: II. Localized, compensatory increases in lateral root growth and rates op nitrate uptake when nitrate supply is restricted to only part of the root system, J. Exp. Bot. 26 (1975) 79-90.

[31] J. Zhu, J.P. Lynch, The contribution of lateral rooting to phosphorus acquisition efficiency in maize (Zea mays) seedlings, Funct. Plant Biol. 31 (2004) 949-958.

[32] G. Mi, F. Chen, Q. Wu, N. Lai, L. Yuan, F. Zhang, Ideotype root architecture for efficient nitrogen acquisition by maize in intensive cropping systems, Sci. China Life Sci. 53 (2010) 
1369-1373.

[33] A.M. Davidson, M. Jennions, A.B. Nicotra, Do invasive species show higher phenotypic plasticity than native species and, if so, is it adaptive? A meta-analysis, Ecol. Lett. 14 (2011) 419-431.

[34] M.D. Ho, J.C. Rosas, K.M. Brown, J.P. Lynch, Root architectural tradeoffs for water and phosphorus acquisition, Funct. Plant Biol. 32 (2005) 737-748.

[35] P. Poot, H. Lambers, Shallow-soil endemics: adaptive advantages and constraints of a specialized root-system morphology, New Phytol. 178 (2008) 371-381.

[32] P. Poot, H. Lambers, Shallow-soil endemics: adaptive advantages and constraints of a specialized root-system morphology, New Phytol. 178 (2008) 371-381. 